\title{
Neutrophil Extracellular Traps Sustain Inflammatory Signals in Ulcerative Colitis
}

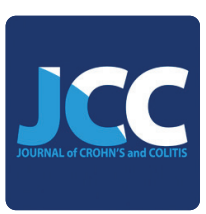

\author{
Vincenzo Dinallo ${ }^{a}, *$, Irene Marafinia,*, Davide Di Fusco ${ }^{a}$, Federica Laudisia, \\ Eleonora Franzè ${ }^{a}$, Antonio Di Graziaa, Michele M. Figliuzzia, \\ Flavio Caprioli ${ }^{b}$, Carmine Stolfia , Ivan Monteleone ${ }^{c}$, Giovanni Monteleone ${ }^{a}$
}

aDepartment of Systems Medicine, University of 'Tor Vergata', Rome, Italy ${ }^{b}$ Department of Pathophysiology and Transplantation, University of Milan, Milan, Italy

'Department of Biomedicine and Prevention, University of 'Tor Vergata', Rome, Italy

Corresponding author: Giovanni Monteleone, Department of Systems Medicine University of 'Tor Vergata', Via Montpellier, 1-00133, Rome, Italy. Tel: +39.06.20903702; Fax:+39.06.72596158; Email: Gi.Monteleone@Med.uniroma2.it

*These two authors contributed equally to the study.

\begin{abstract}
Background and Aims: In ulcerative colitis [UC], mucosal damage occurs in areas that are infiltrated with neutrophils. The antimicrobial function of neutrophils relies in part on the formation of extracellular web-like structures, named neutrophil extracellular traps [NETs]. The formation and/or clearance of aberrant NETs have been associated with several immune diseases. Here we investigated the role of NETs in UC-related inflammation.

Methods: The expression of NET-associated proteins was evaluated in colonic biopsies of patients with Crohn's disease [CD], UC and in normal controls [NC] by Western blotting, immunofluorescence and immunohistochemistry. Colonic biopsies of UC patients were analysed before and after antitumour necrosis factor $\alpha$ [anti-TNF- $\alpha$ ] treatment. The capacity of neutrophils to produce NETs upon activation was tested in vitro. UC lamina propria mononuclear cells [LPMCs] were cultured with NETs in the presence or absence of an extracellular signal-regulated kinase-1/2 [ERK1/2] inhibitor and inflammatory cytokine induction was assessed by real-time polymerase chain reaction and enzyme-linked immunosorbent assay. We also characterized the contribution of NETs in dextran sodium sulfate [DSS]-induced colitis.

Results: NET-associated proteins were over-expressed in inflamed colon of UC patients as compared to CD patients and NC. Circulating neutrophils of UC patients produced NETs in response to TNF- $\alpha$ stimulation, and reduced expression of NET-related proteins and diminished NET formation were seen in patients receiving successful treatment with anti-TNF- $\alpha$. Treatment of UC LPMCs with NETs activated ERK1/2, thus enhancing TNF- $\alpha$ and interleukin-1 $\beta$ [IL-1 $\beta$ ] production. NETs were induced in mice with DSS-colitis and in vivo inhibition of NET release attenuated colitis. Conclusions: Our data show that NET release occurs in UC and suggest a role for NETs in sustaining mucosal inflammation in this disorder.
\end{abstract}

Key Words: NETosis; inflammatory bowel disease; ulcerative colitis; PAD4; neutrophils 


\section{Introduction}

Ulcerative colitis $[\mathrm{UC}]$ is one of the major forms of inflammatory bowel disease $[\mathrm{IBD}]$ in humans. ${ }^{1}$ Although the pathogenesis of this disorder is largely unknown, a large body of evidence suggests that UC arises in genetically predisposed individuals because of an abnormal immune response against luminal antigens, which leads to a persistent and uncontrolled inflammation. ${ }^{2}$ Many immune cells infiltrate the colon of patients with UC, and among these neutrophils are largely present in areas with mucosal damage. Traditionally known as inflammatory cells given their ability to produce a vast array of tissue-damaging molecules, neutrophils are also able to activate pathways that could ultimately promote resolution of the ongoing inflammation and mucosal healing. ${ }^{3}$ Neutrophils are the first immune cells recruited to the site of inflammation, where they recognize, phagocytize and kill pathogens by producing reactive oxygen species with antimicrobial potential, releasing lytic enzymes from their granules, and also by liberating neutrophil extracellular traps [NETs], a process termed 'NETosis', ${ }^{4}$ which can occur with or without cell death. ${ }^{5}$ NETs are web-like structures protruding from the membrane of activated neutrophils, comprising decondensed chromatin, DNA and antimicrobial peptides. Upon activation of neutrophils, protein arginine deiminase-4 [PAD4] promotes histone citrullination and this phenomenon is followed by exocytosis of decondensed chromatin and enzymes, such as neutrophil elastase $[\mathrm{NE}]$ and myeloperoxidase [MPO], which generate the fibrous network of NETs. ${ }^{6}$ Co-expression of granule proteins [e.g. MPO and $\mathrm{NE}$ ] and chromatin, primarily citrullinated histone $\mathrm{H} 3$ [citH3], is considered as evidence of NET release. ${ }^{7}$ More recently, NETs have attracted increased attention in a wide variety of medical conditions such as cancer, thromboembolism, arteriosclerosis and immunemediated diseases. ${ }^{8-10}$ For instance, NETs have been associated with increased production of pro-inflammatory mediators in systemic lupus erythematosus [SLE], ${ }^{11,12}$ and therapies reducing the formation of NETs attenuated inflammation in animal models of SLE. ${ }^{13,14}$ NET release is considered a major mechanism for the production of antibodies against citrullinated peptides in rheumatoid arthritis ${ }^{15}$ and in patients with anti-phospholipid antibodies. ${ }^{16}$ NETs are abundant in secretions of cystic fibrosis patients and are considered to have detrimental effects on lung epithelium. ${ }^{17,18}$ There is also preliminary evidence that NETs can contribute to the impaired healing process seen in the skin of diabetic patients, ${ }^{19}$ and increased NET production has been documented in the peripheral circulation and skin lesions of psoriasis patients. ${ }^{20}$ NETs have also been described in colonic mucosal samples of UC patients, ${ }^{21}$ but their contribution to the inflammatory response that occurs in this disease remains to be elucidated.

Here we investigated the role of NETs in the control of mucosal inflammation in UC. By using both human and mouse models of colitis, we show that UC-associated inflammation is marked by NET release and provide evidence that NETs can amplify pathogenic signals in the gut.

\section{Materials and Methods}

\subsection{Patients and samples}

Mucosal biopsies were taken from the inflamed areas of nine patients with colonic Crohn's disease [CD] and nine patients with UC undergoing colonoscopy for clinically active disease at the Gastrointestinal Unit of either Tor Vergata University [Rome] or Fondazione IRCCS Cà Granda, Ospedale Maggiore Policlinico [Milan]. Moreover, paired biopsies were taken from the inflamed and uninflamed mucosa of four additional patients with UC. Three additional UC patients were treated with infliximab [IFX]: each patient received a total of three IFX infusions [ $5 \mathrm{mg} / \mathrm{kg}$ ] at weeks 0,2 and 6 . Six colonic biopsies were collected during a flexible sigmoidoscopy from the sigmoid colon before the first and after the third IFX infusion. In all these patients, endoscopic improvement was documented after the last IFX infusion. Additionally, surgical specimens were taken from seven patients with UC undergoing surgery for a chronic active disease that was poorly responsive to medical treatment. Surgical specimens were taken from both involved and uninvolved mucosa. Controls included biopsies taken from macroscopically and microscopically unaffected colonic areas of 12 patients who underwent surgery for colon cancer. Informed consent was obtained from all the patients, and the local ethics committees approved the study protocol.

\subsection{Experimental colitis}

All reagents were from Sigma-Aldrich unless otherwise specified. Eight- to 9-week-old female Balb/c mice received either regular drinking water [control] or 3\% dextran sulfate sodium [DSS]. Both groups of animals had similar daily fluid intake. Weight changes were recorded daily and DSS-treated mice were killed at day 8 or day 5 , and tissues were collected for RNA and protein analysis. In parallel experiments, DSS-treated mice were given intraperitoneally streptonigrin, a selective PAD4 inhibitor, once a day [streptonigrin: $0.4 \mathrm{mg} / \mathrm{kg}$ in $100 \mu \mathrm{l}$ PBS per mouse], ${ }^{22,23}$ starting from day 4 after DSS treatment. Weight changes, stool consistency and rectal bleeding were recorded daily as previously described, ${ }^{24}$ mice were killed at day 8 , and tissues were collected for histology and mRNA/protein extraction. All animal experiments were approved by animal ethics committees, according to Italian legislation on animal experiments.

\subsection{Histopathological analysis}

Cryosections of mouse colon samples were stained with haematoxylin and eosin [H\&E], and histological score was measured by three pathologists with long-standing expertise in colitis, as previously described. ${ }^{25}$

\subsection{Immunohistochemistry}

Immunohistochemistry was performed on archival formalin-fixed paraffin-embedded colonic sections of five patients with UC and five normal controls [NC]. Additional sections were prepared from samples taken from the inflamed and non-inflamed areas of four patients with UC. Colonic sections of three patients with UC before and after IFX treatment were also analysed. The sections were deparaffinized and dehydrated through xylene and ethanol and antigen retrieval was performed in citrate buffer [ $\mathrm{pH}$ 6.0] for $20 \mathrm{~min}$ in a microwave. Immunohistochemical staining was performed using a mouse monoclonal antibody directed against human PAD4 [1:5000 final dilution; Novus Biologicals] at room temperature for $1 \mathrm{~h}$ followed by a biotin-free horseradish peroxidase [HRP]-polymer detection technology with 3,3'diaminobenzidine [DAB] as a chromogen [UltraVision kit, Lab Vision]. The sections were counterstained with haematoxylin, dehydrated and mounted. Isotype control IgG-stained sections were prepared under identical immunohistochemical conditions as described above, replacing the primary PAD4 antibody with a purified control isotype [R\&D Systems].

\subsection{Immunofluorescence}

Immunofluorescence was performed on archival frozen sections of five UC and five NC mucosal specimens and on cryosections of 
colonic samples of mice treated as described above. Samples were embedded in a cryostat mounting medium [Neg-50 Frozen Section Medium, Thermo Scientific], snap frozen and stored at $-80^{\circ} \mathrm{C}$. Sections $6 \mu \mathrm{m}$ thick were mounted onto superfrost plus glass slides [Thermo Scientific] and fixed in 4\% paraformaldehyde [PFA] for $10 \mathrm{~min}$ at $4^{\circ} \mathrm{C}$. Slides were washed three times with PBS, and treated with $0.1 \%$ Triton X-100 for $20 \mathrm{~min}$ at room temperature [RT]. Blocking was performed with a $10 \%$ normal goat serum PBS solution for $1 \mathrm{~h}$ at RT. Slides were then incubated overnight at $4^{\circ} \mathrm{C}$ with mouse anti-human MPO [1:100 final dilution; Abcam], rabbit antihuman NE [1:70 final dilution; Abcam] or rabbit anti-human/mouse citH3 [1:100 final dilution; Abcam]. After washing three times with PBS, slides were incubated for $1 \mathrm{~h}$ at RT with specific secondary antibodies coupled with Alexa Fluor Dyes [1:2000 final dilution; Invitrogen]. Coverslips were mounted on glass slides using ProLong Gold antifade reagent with DAPI [Invitrogen] to counterstain the DNA. Images were acquired on a Leica DMI 4000 B fluorescence microscope [Leica].

\subsection{Induction and isolation of NETs}

Neutrophils were isolated from whole blood of UC patients and NC by negative selection using MACSxpress Beads [Miltenyi Biotec] and were seeded on eight-well Nunc Lab-Tek II CC2 Chamber Slides [Thermo Fisher Scientific] $\left[2.5 \times 10^{5}\right.$ cells per well] for $30 \mathrm{~min}$ in RPMI1640 medium at $37^{\circ} \mathrm{C}$ and $5 \% \mathrm{CO}_{2}$. After adhesion, the cells were either left unstimulated or stimulated with $20 \mathrm{ng} / \mathrm{ml}$ tumour necrosis factor- $\alpha$ [TNF- $\alpha$, R\&D Systems], $20 \mathrm{ng} / \mathrm{ml}$ interleukin$1 \beta$ [IL-1 $\beta$, R\&D Systems], $25 \mathrm{ng} / \mathrm{ml}$ IL-6 [R\&D Systems], $100 \mathrm{ng} /$ $\mathrm{ml}$ interferon- $\gamma$ [IFN- $\gamma$, Peprotech], $100 \mathrm{ng} / \mathrm{ml}$ lipopolysaccharide [LPS, Sigma-Aldrich], $1 \mu \mathrm{g} / \mathrm{ml}$ cytosine-phosphate-guanine [CpG] oligodeoxynucleotide [Invitrogen] and $50 \mathrm{nM}$ phorbol myristate acetate [PMA, eBioscience] for 3.5 hs. To isolate NETs, UC neutrophils $\left[2 \times 10^{6}\right.$ cells per well] were seeded in six-well plates for $30 \mathrm{~min}$ in $1 \mathrm{ml}$ RPMI1640 medium and then stimulated with $50 \mathrm{nM}$ PMA. After 3.5 h, cells were washed twice with fresh RPMI1640 medium and the NETs were collected by extensively pipetting with $1 \mathrm{ml}$ RPMI1640 medium and centrifuged the resulting supernatant [20 $\times g$ for $5 \mathrm{~min}]$.

\subsection{In vitro NET visualization}

Neutrophils were stimulated as described above and then fixed, permeabilized and blocked for immunofluorescence staining. Cells were incubated with mouse anti-human MPO [1:100 final dilution; Abcam] and rabbit anti-human NE [1:70 final dilution; Abcam] followed by specific secondary antibodies coupled with Alexa Fluor dyes. Coverslips were mounted on glass slides using ProLong Gold antifade reagent with DAPI to counterstain the DNA. NETs were counted in four different fields.

\subsection{LPMC isolation and culture}

Lamina propria mononuclear cells [LPMCs] were isolated as previously described. ${ }^{26}$ Briefly, fresh surgical colonic specimens of five UC patients were freed of mucus and epithelial cells in sequential steps with dithiothreitol [DTT] and ethylenediminetetracetic acid [EDTA] and then digested with liberase-tm $[0.2 \mathrm{mg} / \mathrm{ml}$; Roche $]$ and DNase I [0.2 mg/ml; Roche]. LPMCs were resuspended $\left[1.5 \times 10^{6} / \mathrm{ml}\right]$ in RPMI1640 supplemented with penicillin $[100 \mu \mathrm{g} / \mathrm{ml}] / \mathrm{streptomycin}$ $[100 \mu \mathrm{g} / \mathrm{ml}]$ and $10 \%$ fetal bovine serum [FBS] heated at $70^{\circ} \mathrm{C}$ to avoid NET degradation by nucleases. ${ }^{27}$ LPMCs were cultured in the presence or absence of either undigested or digested NETs [1:3 final ratio]. NET digestion was obtained by treating NET DNA with DNase I [ $5 \mu \mathrm{g} / \mathrm{ml}$; Roche] for $1 \mathrm{~h}$ at $37^{\circ} \mathrm{C}$ and checked by visualizing the digested products on a $1 \%$ agarose gel stained with ethidium bromide [Bio-Rad Laboratories] as an intercalating agent. After $24 \mathrm{~h}$ of culture, LPMCs were analysed by flow cytometry or used to extract RNA, while cell-free supernatants were harvested and analysed for TNF- $\alpha$ and IL- $1 \beta$ protein content by an enzyme-linked immunosorbent assay [ELISA]. To investigate the mechanism by which NETs stimulate inflammatory cytokine synthesis, UC LPMCs were stimulated with NETs. After 5-60 min, total proteins were extracted and analysed for the content of both phosphorylated and total extracellular signal-regulated kinase-1/2 [ERK1/2], p38 and c-Jun $\mathrm{N}$-terminal kinase [JNK] by Western blotting. In parallel, LPMCs were pre-incubated with PD98059 [20 $\mu \mathrm{M}$; EMD Millipore], a selective inhibitor of ERK1/2, or DMSO [vehicle] for $1 \mathrm{~h}$ and then either left untreated or treated with NETs for $24 \mathrm{~h}$. After this, cellfree supernatants were used to assess TNF- $\alpha$ and IL- $1 \beta$ protein content by ELISA. UC LPMCs were also cultured in the presence or absence of NETs isolated from UC or NC neutrophils. To investigate whether NET-associated IL- $1 \beta$ contributes to the biological function of NETs, ${ }^{28}$ UC LPMCs were pre-incubated with Anakinra, an IL-1 receptor antagonist [100 ng/ml; BioLegend Inc.] and $1 \mathrm{~h}$ later stimulated with UC NETs.

\subsection{Flow cytometry}

To assess cell viability, neutrophils and LPMCs were cultured as indicated above, and the percentage of annexin $\mathrm{V}$ and/or propidium iodide-positive cells was assessed by flow cytometry according to the manufacturer's instructions [Immunotech].

\subsection{Western blotting}

Samples were lysed on ice in buffer containing $10 \mathrm{mM}$ Hepes [pH 7.9], $10 \mathrm{mM} \mathrm{KCl}, 0.1 \mathrm{mM}$ EDTA, $0.2 \mathrm{mM}$ ethylene glycol-bis [ $\beta$-aminoethyl ether]-N,N, $\mathrm{N}^{\prime}, \mathrm{N}^{\prime}$-tetraacetic acid [EGTA] and $0.5 \%$ Nonidet P40 supplemented with $1 \mathrm{mM}$ DTT, $10 \mathrm{mg} / \mathrm{ml}$ aprotinin, $10 \mathrm{mg} / \mathrm{ml}$ leupeptin, $1 \mathrm{mM}$ phenylmethylsulfonyl fluoride [PMSF], $1 \mathrm{mM} \mathrm{Na} \mathrm{VO}_{4}$ and $1 \mathrm{mM} \mathrm{NaF}$. Lysates were clarified by centrifugation and separated by sodium dodecyl sulphate [SDS]-polyacrylamide gel electrophoresis. Blots were incubated with antibodies against human PAD4 [1:1000 final dilution; Novus Biologicals] and mouse PAD4 [1:1000 final dilution; Abcam], MPO [1:1000 final dilution; Abcam], NE [1:1000 final dilution; Abcam], citH3 [1:1000 final dilution; Abcam], followed by specific secondary antibodies conjugated to HRP [1:20 000 final dilution; Dako]. p-ERK1/2, p-p38 and p-JNK were detected using a mouse anti-human p-ERK1/2 antibody [1:500 final dilution; Santa Cruz Biotechnology], rabbit anti-mouse p-p38 antibody [1:1000 final dilution; EMD Millipore Corporation] and mouse anti-human p-JNK antibody [1:500 final dilution; Santa Cruz Biotechnology], respectively, followed by HRP-conjugated secondary IgG monoclonal antibodies [all used at 1:20 000 final dilution; Dako]. The reaction was detected with a sensitive ECL kit [Thermo Fisher]. After analysis, blots were stripped and incubated with the following internal loading controls: rabbit anti-human total ERK1/2 antibody [1:500 final dilution; Santa Cruz Biotechnology], mouse anti-human total p38 antibody and mouse anti-human total JNK antibody [both at 1:500 final dilution; Santa Cruz Biotechnology], followed by HRP-conjugated secondary antibodies [1:20 000 final dilution; Dako]. After analysis, each blot was stripped and incubated with a mouse monoclonal $\beta$-actin antibody [1:5000 final dilution; Sigma-Aldrich] to ascertain equivalent loading of the lanes. 
A
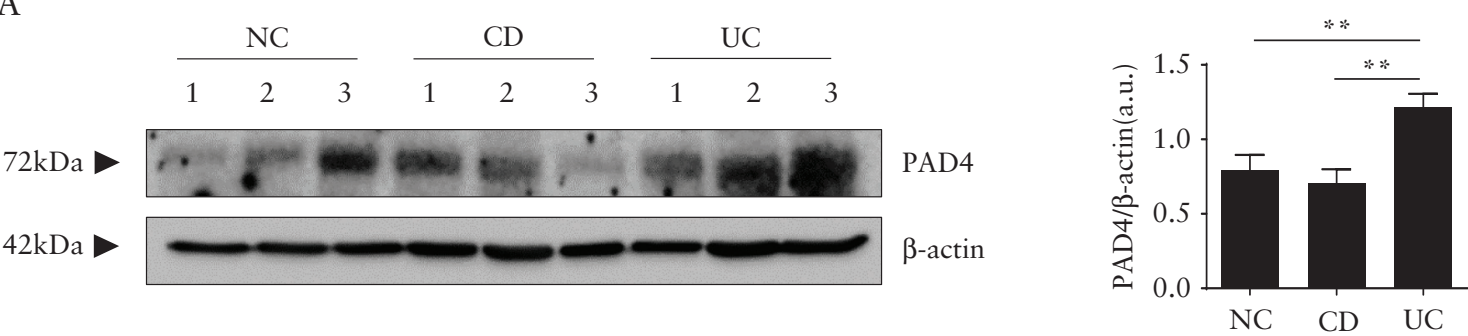

B

PAD4

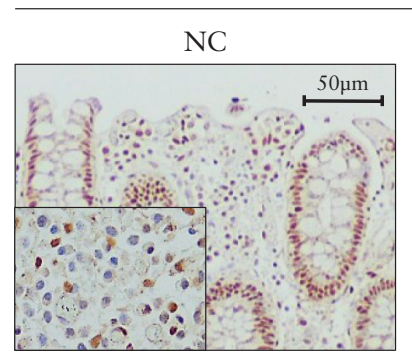

(2)
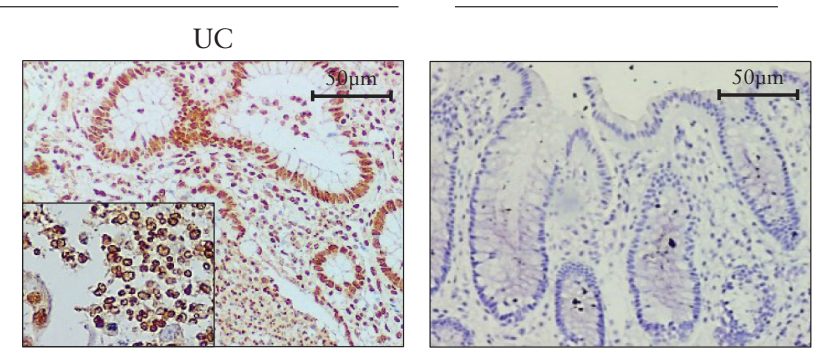

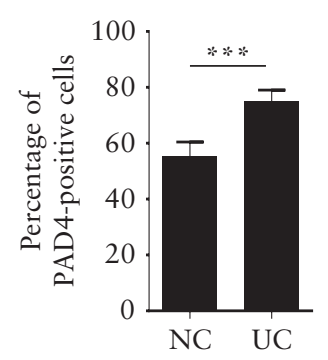

C
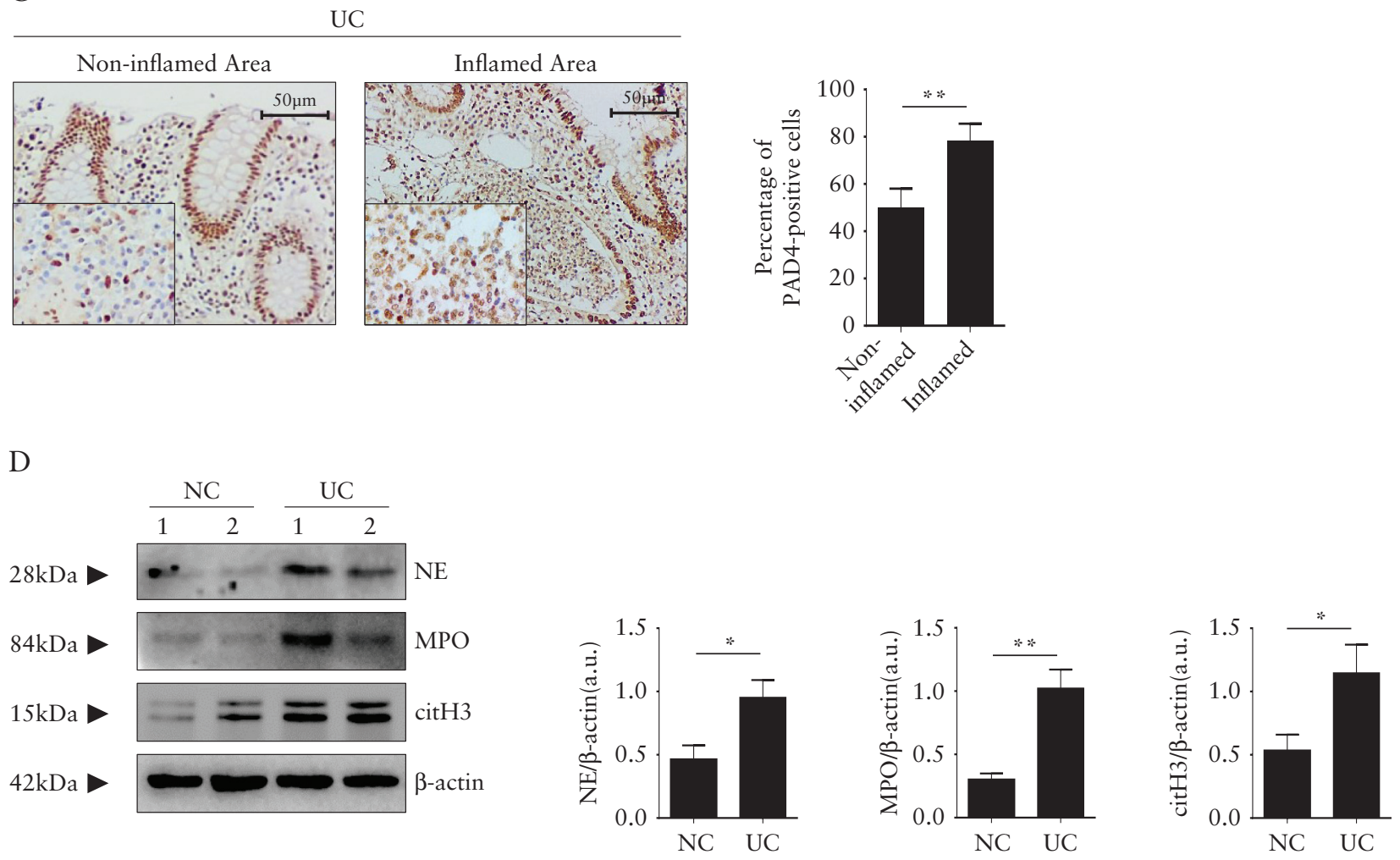

Figure 1. Neutrophil extracellular trap [NET]-associated proteins are up-regulated in ulcerative colitis. [A] Total proteins were extracted from the colon samples of nine normal controls [NC], nine Crohn's disease [CD] patients and nine ulcerative colitis [UC] patients and analysed for PAD4 by Western blotting. The blot is representative of three separate experiments in which similar results were obtained. $\beta$-Actin was used as a loading control. The right inset shows quantitative analysis of PAD4/ $\beta$-actin ratio as measured by densitometry scanning of all Western blots. Values are expressed in arbitrary units [a.u.] [**p<0.01]. [B] Representative immunohistochemical images showing PAD4-positive cells in colon sections of NC and UC patients. Staining with isotype control lgG is also shown. Right panel: percentage of PAD4-positive cells. Values are mean \pm SD [*** $p<0.005]$. [C] Representative immunohistochemical images showing PAD4positive cells in inflamed and non-inflamed colonic mucosa of one UC patient. Right panel: percentage of PAD4-positive cells. Values are mean \pm SD [*** $p<0.01$ ]. [D] Representative Western blot showing NE, MPO and citH3 expression in the colon samples of NC and UC patients. $\beta$-Actin was used as a loading control. The blot is representative of three separate experiments in which similar results were obtained. The right insets show quantitative analysis of NE, MPO and citH3/ $\beta$-actin ratios as measured by densitometry scanning of all Western blots. Values are expressed in arbitrary units [a.u.] [ $\left.{ }^{*} p<0.05,{ }^{* *} p<0.01\right]$. PAD4, protein arginine deiminase-4; NE, neutrophil elastase; MPO, myeloperoxidase; citH3, citrullinated histone $\mathrm{H} 3$. 


\subsection{RNA extraction, cDNA preparation and} real-time PCR

RNA was extracted using a PureLink mRNA Mini Kit [Thermo Fisher Scientific], according to the manufacturer's instructions. A constant amount of RNA [ $1 \mu \mathrm{g}$ per sample] was reverse transcribed into complementary DNA [cDNA] and this was amplified using the following conditions: denaturation for $1 \mathrm{~min}$ at $95^{\circ} \mathrm{C}$; annealing for $30 \mathrm{~s}$ at $58^{\circ} \mathrm{C}$ for human IL- $1 \beta$, IFN- $\gamma$, mouse TNF- $\alpha$ and lipocalin-2 [LCN2], $59^{\circ} \mathrm{C}$ for human PAD4, $61^{\circ} \mathrm{C}$ for mouse $\mathrm{IL}-1 \beta, 62^{\circ} \mathrm{C}$ for human TNF- $\alpha$, transforming growth factor- $\beta 1$ [TGF- $\beta 1]$ and mouse PAD4, and $60^{\circ} \mathrm{C}$ for $\beta$-actin; and finally $30 \mathrm{~s}$ of extension at $72^{\circ} \mathrm{C}$. Primer sequences were as follows: human PAD4 forward 5'-CAGGGGACATTGATCCGTGTG-3', reverse 5'-GGGAGGCGTTGATGCTGAA-3'; IL-1 $\beta$ forward 5'-AGAATGA CCTGAGCACCTTC-3', reverse 5'-GCACATAAGCCTCGTTAT CC-3'; IFN- $\gamma$ forward 5'-TGGAGACCATCAAGGAAGAC-3', reverse 5 '-GCGTTGGACATTCAAGTCAG-3'; TNF- $\alpha$ forward 5'-AGGCGGTGCTTGTTCCTCAG-3', reverse 5'-GGCTACAGGC TTGTCACTCG-3'; TGF- $\beta 1$ forward 5'-CGACTACTACGCCAA GGAGG-3', reverse 5'-GAGAGCAACACGGGTTCAGG-3'; mouse PAD4 forward 5'-TGACCAATGGATGCAGGACG-3', reverse 5'-CTCTGTCCCTCGGGGAGTC-3'; LCN2 forward 5'-CCAGGA CTCAACTCAGAAC-3', reverse 5'-GCTCATAGATGGTGCTGTAC-3'; IL-1 $\beta$ forward 5'-TCAGGCAGGCAGTATCACTC-3', reverse 5'-CTAATGGGAACGTCACACACC-3'; TNF- $\alpha$ forward 5'-ACCC TCACACTCAGATCATC-3' , reverse 5'-GAGTAGACAAGGTACAA
CCC-3'; $\beta$-actin [forward $5^{\prime}$-AAGATGACCCAGATCATGTTTGA GACC-3', reverse 5'-AGCCAGTCCAGACGCAGGAT-3'] was used as a housekeeping gene. Gene expression was calculated using the $\Delta \Delta \mathrm{Ct}$ algorithm.

\subsection{ELISA}

LPMC culture supernatants were analysed for TNF- $\alpha$ and IL- $1 \beta$ contens using specific ELISA kits [R\&D Systems] in accordance with the manufacturer's instructions.

\subsection{Statistical analysis}

Differences between groups were compared using Student's $t$-test. All analyses were performed using GraphPad Prism version 5.00 software for Windows [GraphPad Software, www.graphpad.com].

\section{Results}

\subsection{NET-associated proteins are up-regulated in} patients with UC

We evaluated the expression of NET-associated proteins in inflamed colonic samples of IBD patients and NC. To this end, we initially assessed expression of PAD4, as this protein acts as a driver of NET release and PAD4-null mice are unable to make NETs. ${ }^{29}$ Western blotting analysis and quantification of immunoblots showed that PAD4 expression was significantly increased in inflamed mucosa
A

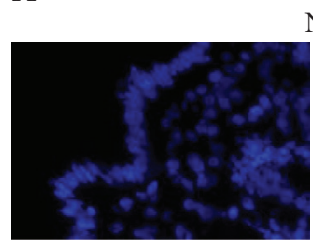

$\mathrm{NC}$
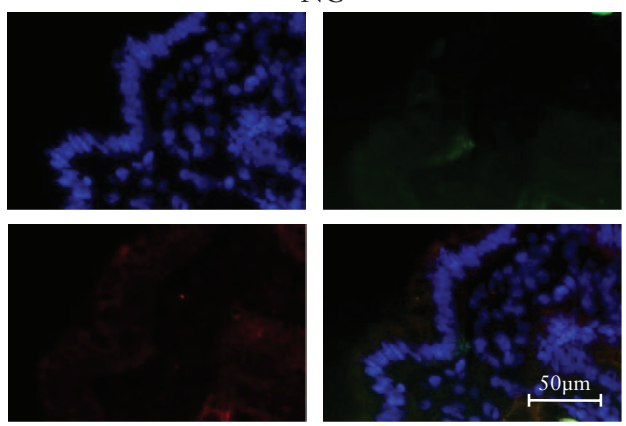

B

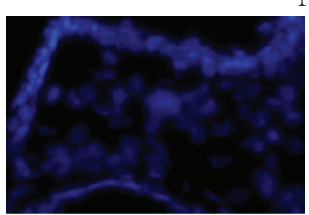

NC
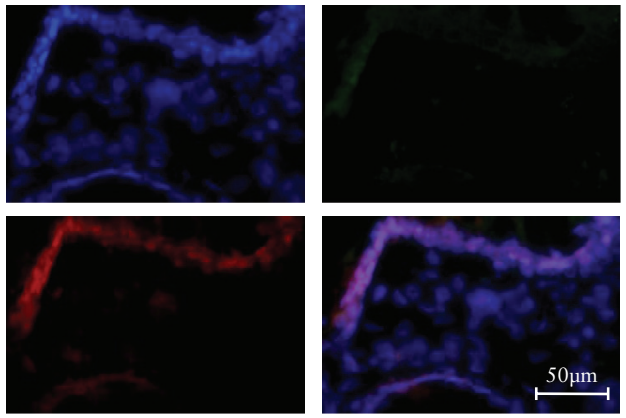

UC
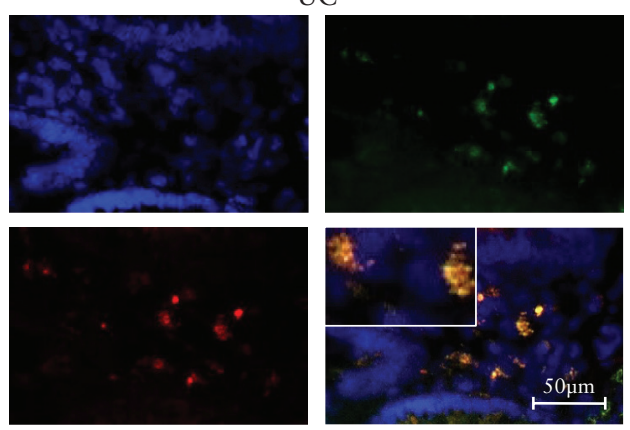

DNA; NE; MPO

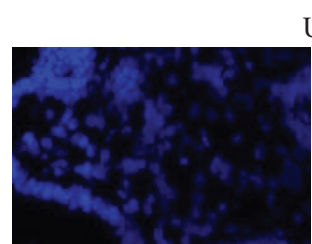

UC
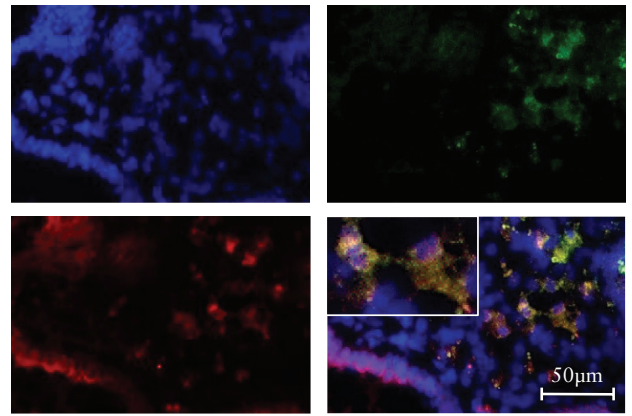

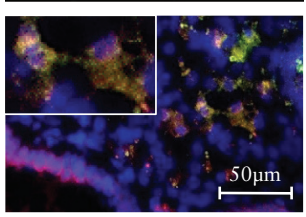

DNA; MPO; citH3

Figure 2. Neutrophil extracellular traps [NETs] are evident in inflamed colon of ulcerative colitis [UC] patients. [A] Representative images of doubleimmunofluorescence staining of colon sections of normal controls [NC] and UC patients for myeloperoxidase [MPO, red] and neutrophil elastase [NE, green]. Co-localization of MPO and NE [yellow staining] together with DNA [DAPI, blue] is indicative of NETs. [B] Representative images of double-immunofluorescence staining of colon sections of NC and UC patients for MPO [green] and citrullinated histone $\mathrm{H} 3$ [citH3, red]. Co-localization of MPO and citH3 [yellow staining] together with DNA [DAPI, blue] is indicative of NETs. 
of UC patients as compared to $\mathrm{CD}$ patients and $\mathrm{NC}$, while there was no significant change between $\mathrm{CD}$ and NC [Figure 1A]. Immunohistochemistry confirmed such data and showed that PAD4expressing cells were abundantly present in the lamina propria of UC patients as compared to NC [Figure 1B]; interestingly, some of the PAD4-positive cells exhibited morphological features of neutrophils [Figure 1B, insets]. PAD4 was also expressed by epithelial cells in normal and inflamed conditions, but staining was more intense in UC [Figure 1B]. In the majority of PAD4-positive cells, staining was both cytoplasmic and nuclear, thus confirming previous studies showing that PAD4 can be detected in both compartments. ${ }^{30}$ Analysis of paired colonic sections of UC patients showed a more pronounced PAD4 expression in the inflamed areas as compared to the uninvolved mucosa of the same patients [Figure 1C]. Next, we evaluated the content of NE, MPO and citH3, three additional components of NETs, by Western blotting. In line with data from previous studies, ${ }^{21,31,32}$ the expression of each of these proteins was enhanced in UC as compared to NC [Figure 1D]. Furthermore, a double-immunofluorescence assay showed that, in UC mucosa, these proteins co-localized [Figure 2A, B].

\subsection{Activated neutrophils of UC patients produce NETs}

In subsequent studies, we tested the capacity of neutrophils to produce NETs upon activation. Neutrophils were isolated from UC patients and $\mathrm{NC}$ and stimulated in vitro with various inflammatory cytokines and bacterial products/components, which are considered to play a role in UC pathogenesis. ${ }^{2}$ A significant increase of NETs was seen following stimulation of UC neutrophils with TNF- $\alpha$, LPS and PMA, while the remaining stimuli were unable to induce NETs [Figure 3A].

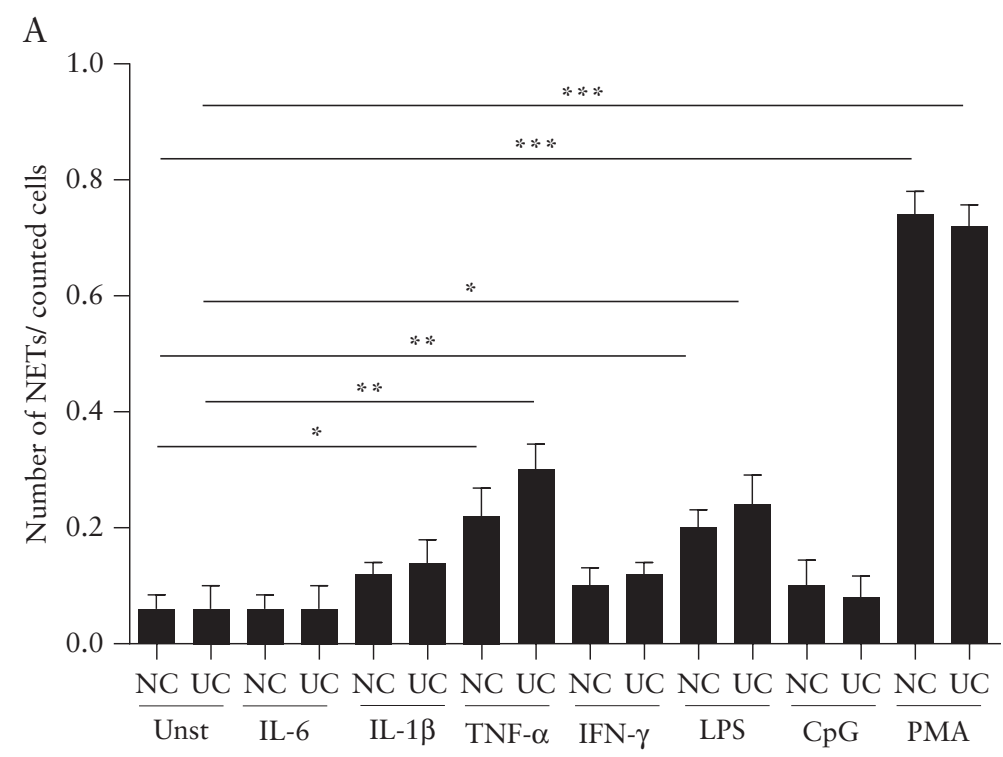

B
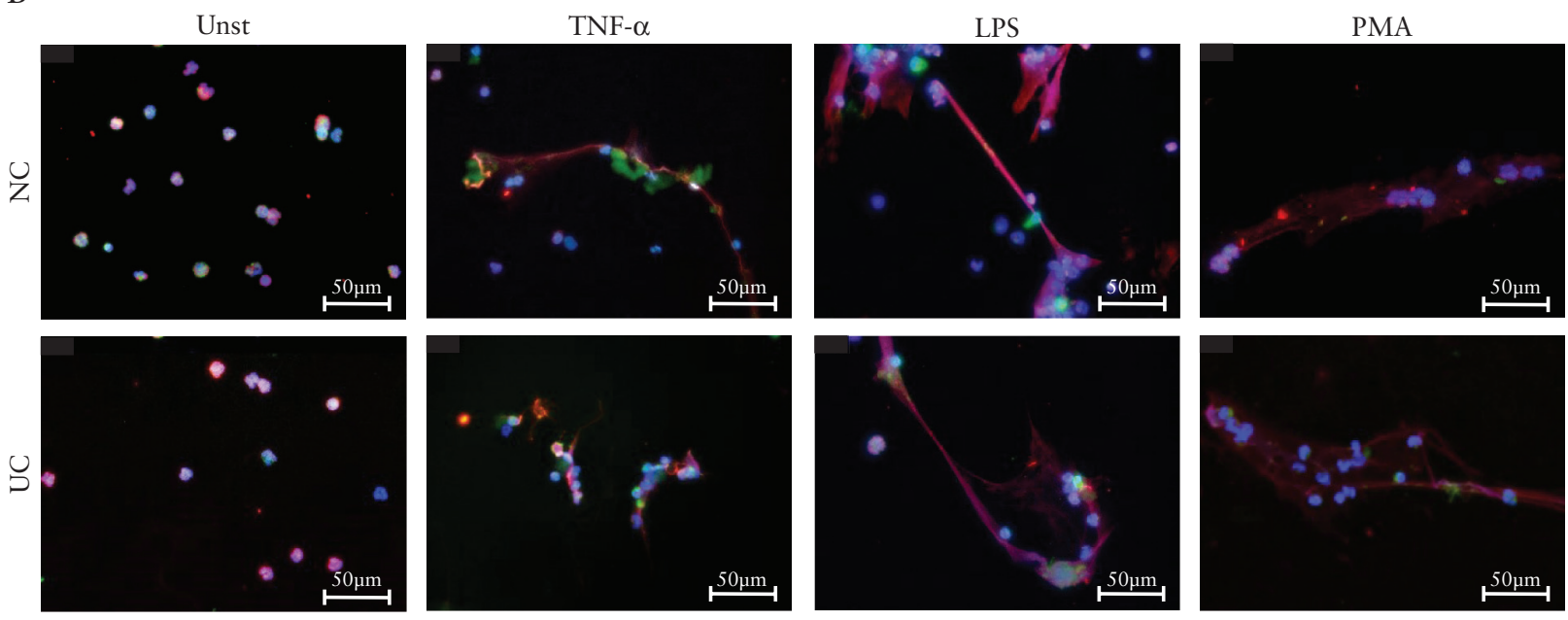

DNA; NE; MPO

Figure 3. Neutrophils produce neutrophil extracellular traps [NETs] upon stimulation. [A] Quantitative analysis of NETs released by neutrophils isolated from peripheral blood of normal controls [NC] and ulcerative colitis [UC] patients in response to IL-6, IL-1 $\beta$, TNF- $\alpha$, IFN- $\gamma$, LPS, CpG and PMA. NETs were counted in four different fields and data indicate mean \pm SEM of five independent experiments $\left[{ }^{*} p<0.05,{ }^{* *} p<0.01,{ }^{* * *} p<0.005\right]$. [B] Representative images of doubleimmunofluorescence staining of unstimulated or stimulated [TNF- $\alpha$, LPS and PMA] neutrophils isolated from peripheral blood of NC and UC patients for myeloperoxidase [MPO, red] and neutrophil elastase [NE, green]. Co-localization of MPO and NE [yellow staining] together with DNA [DAPI, blue] is indicative of NETs. 
Induction of NETs was not restricted to UC, as control neutrophils produced NETs upon activation [Figure 3A, B]. This suggests that, in UC mucosa, the increased NET release is not due to a specific alteration of neutrophils but rather reflects the greater neutrophil influx and chronic stimulation of such cells by inflammatory cytokines. Furthermore, release of NETs by neutrophils was not secondary to induction of cell death, as no significant increase in cell death was seen following stimulation of neutrophils with TNF- $\alpha$, LPS and PMA [Supplementary Figure 1].

\subsection{Successful treatment of UC with IFX is} associated with diminished presence of NETs in the gut

Since the above data indicate that TNF- $\alpha$ promotes NET release, we assessed whether, in UC, the IFX-mediated therapeutic benefit was associated with changes in NET production. To this end, PAD4 expression was analysed by immunohistochemistry in intestinal colonic samples from UC patients before and after successful induction therapy with IFX. PAD4-positive cells were significantly reduced by IFX [Figure 4A]. Consistently, IFX treatment reduced expression of additional NET-associated proteins [Figure 4B].
3.4. NETs enhance the production of TNF- $\alpha$ and IL-1 $\beta$ in UC LPMCs through ERK/MAPK activation

Next, we examined whether NETs contribute to amplify inflammatory signals in UC. To this end, UC LPMCs were cultured in the presence or absence of NETs. Treatment of UC LPMCs with NETs significantly enhanced IL- $1 \beta$ and TNF- $\alpha$ RNA transcripts, while there was no increase in IFN- $\gamma$ and TGF- $\beta 1$ transcripts [Figure 5A]. Consistently, NETs significantly increased IL- $1 \beta$ and TNF- $\alpha$ protein secretion [Figure 5B]. Induction of these two cytokines probably reflects the stimulatory effect of NETs on LPMCs, as no increase in IL-1 $\beta$ and TNF- $\alpha$ and production was seen in UC LPMCs treated with NETs digested by DNase I [Figure 5B]. No change in LPMC viability was documented following treatment with NETs [Figure 5C]. The inducing effect of NETs on inflammatory cytokines was specific for UC NETs as no change in the production of IL- $1 \beta$ and TNF- $\alpha$ was seen when UC LPMCs were cultured in the presence of $\mathrm{NC}$ NETs [Figure 5D]. As a recent study has shown that UC NETs contain bioactive IL-1 $\beta,{ }^{28}$ we next evaluated whether the inducing effect of UC NETs on inflammatory cytokines was dependent on IL-1 $\beta$. For this purpose, UC LPMC were pre-incubated with Anakinra for $1 \mathrm{~h}$ and then treated with UC NETs. Anakinra abrogated the
A

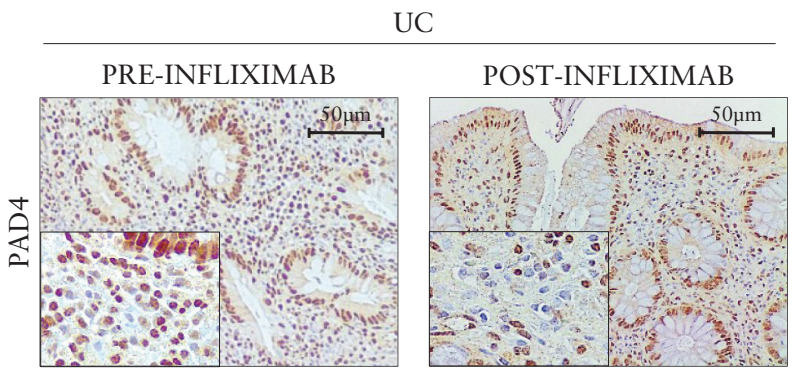

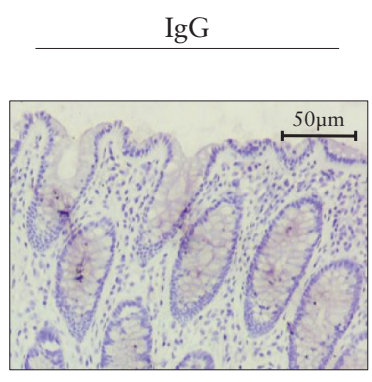

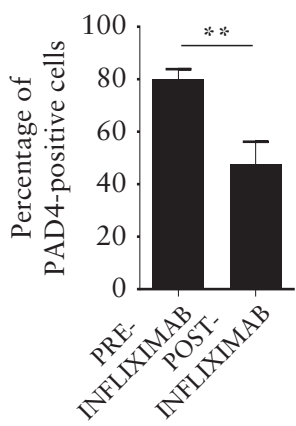

B

PRE-

INFLIXIMAB
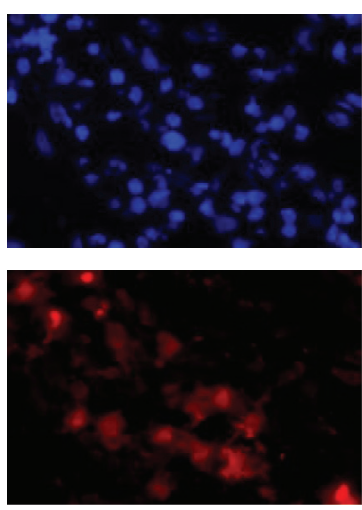
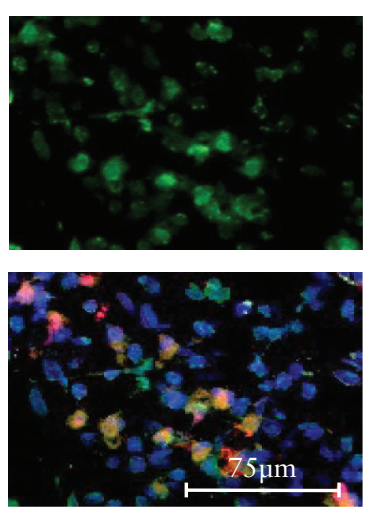

POST-

INFLIXIMAB
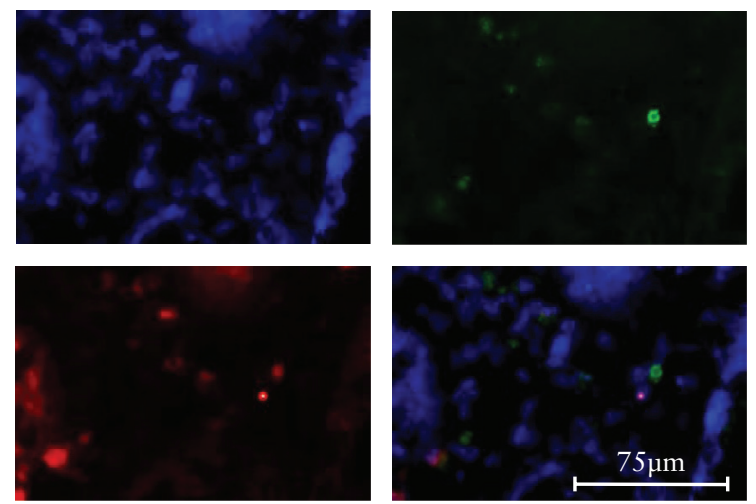

Figure 4. Infliximab therapy reduces the colonic presence of neutrophil extracellular traps [NETs] in ulcerative colitis [UC] patients. [A] Representative immunohistochemical images showing protein arginine deiminase-4 [PAD4]-positive cells in colon sections of UC patients before and after infliximab therapy. Staining with isotype control IgG is also shown. Right panel: percentage of PAD4-positive cells. Values are mean \pm SD [** $p<0.01$ ]. [B] Representative doubleimmunofluorescence staining of colon sections of UC patients, before and after infliximab therapy, stained for myeloperoxidase [MPO, green] and citrullinated histone $\mathrm{H} 3$ [citH3, red]. Co-localization of MPO and citH3 [yellow staining] together with DNA [DAPI, blue] is indicative of NETs. 
A
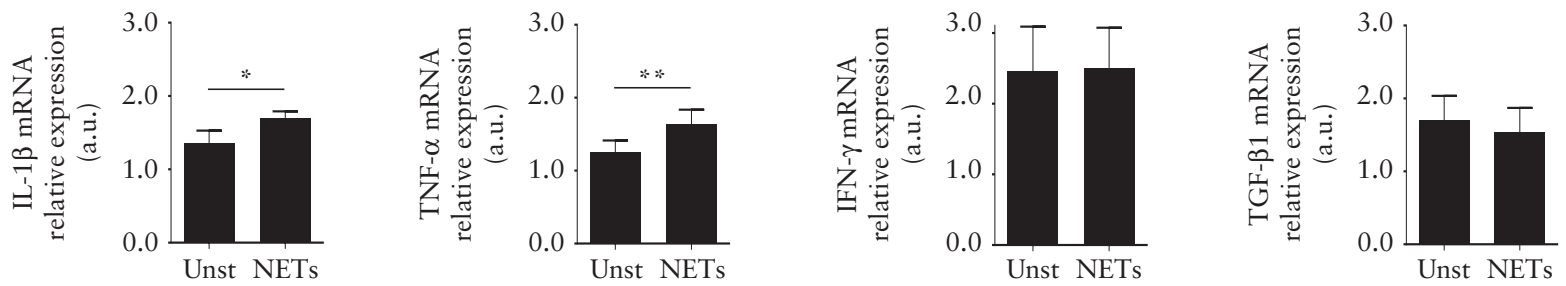

B
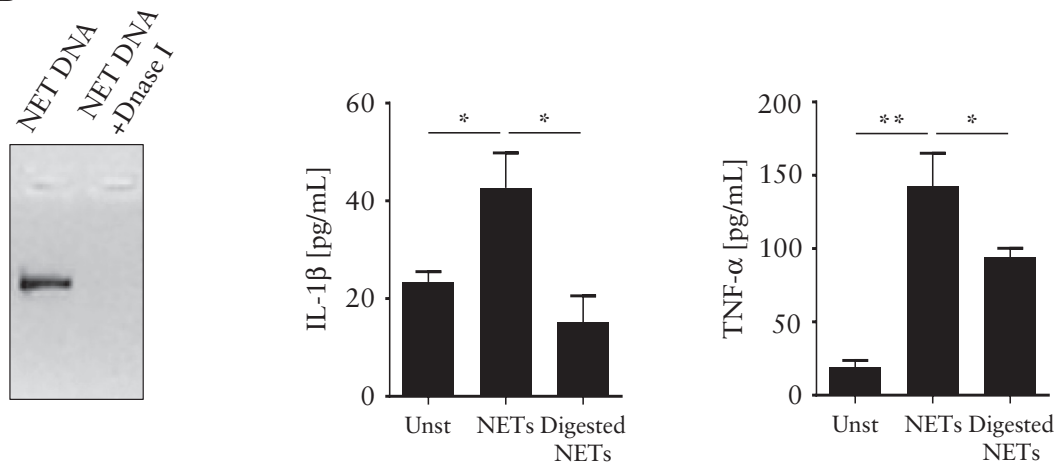

C
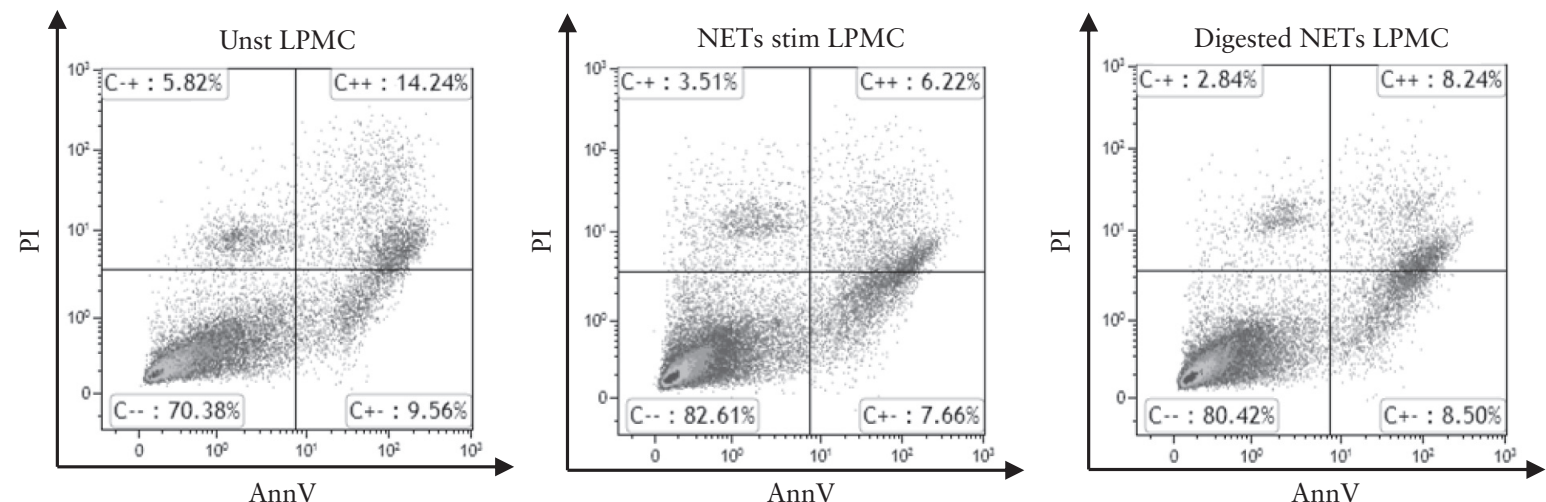

D
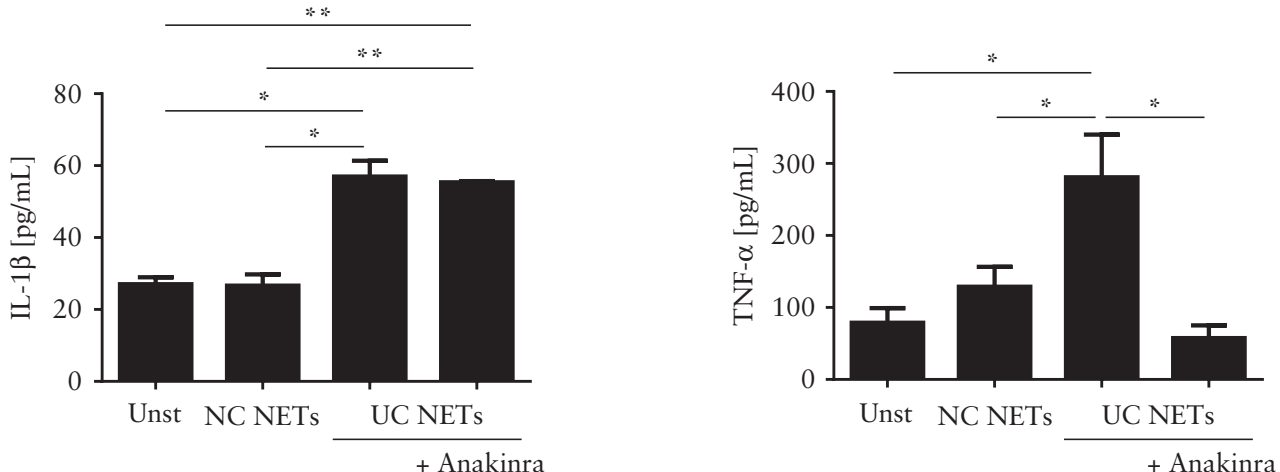

Figure 5. Ulcerative colitis [UC] neutrophil extracellular traps [NETs] enhance the production ofTNF- $\alpha$ and IL-1 $\beta$ in UC lamina propria mononuclear cells [LPMCs]. [A] UC LPMCs were treated with or without NETs for $24 \mathrm{~h}$ and TNF- $\alpha, \mathrm{IL}-1 \beta$, IFN- $\gamma$ and TGF- $\beta 1$ mRNA transcripts were analysed by real-time PCR. Data are mean \pm SEM of five experiments [ ${ }^{*} p<0.05,{ }^{*} p<0.01$ ]. Values are expressed in arbitrary units [a.u.]. [B] UC LPMCs were either left untreated or treated with NETs or digested NETs for $24 \mathrm{~h}$ and DNA samples were separated on a $1 \%$ agarose gel electrophoresis. The band indicates the NET DNA stained with ethidium bromide as an intercalating agent. Right panels: in parallel, cells were treated as above andTNF- $\alpha$ and IL-1 $\beta$ protein secretion was analysed in cell-free supernatants by ELISA. Data are mean \pm SEM of five experiments $\left[{ }^{*} p<0.05,{ }^{* *} p<0.01\right.$ ]. [C] Representative flow cytometry dot plots showing AnnV- and/or PI-positive UC LPMCs either left untreated or treated with NETs or digested NETs for $24 \mathrm{~h}$. Numbers indicate the percentage of cells in the designated gates. One of three representative experiments is shown. [D] UC LPMCs were cultured in the presence or absence of NETs isolated from UC or NC neutrophils. In parallel UC LPMCs were pre-incubated with Anakinra, an IL-1 receptor antagonist, for $1 \mathrm{~h}$ and then treated with UC NETs for $24 \mathrm{~h}$. IL-1 $\beta$ and TNF- $\alpha$ protein secretion was analysed in cell-free supernatants by ELISA. Data are mean \pm SEM of three experiments $\left[* p \leq 0.05,{ }^{*} p \leq 0.01\right]$. 
stimulatory effect of UC NETs on TNF- $\alpha$ without changing IL-1 $\beta$ protein secretion [Figure 5D].

To investigate the mechanisms by which NETs stimulate inflammatory cytokine production, we evaluated the expression of active forms of mitogen-activated protein kinases [MAPKs] in UC LPMCs treated or not with NETs by Western blotting. ERK1/2 phosphorylation but not activation of $\mathrm{p} 38$ and JNK was enhanced by NETs [Figure 6A]. Treatment of UC LPMCs with a specific inhibitor of ERK1/2 activation [PD98059] significantly reverted the positive effect of NETs on IL- $1 \beta$ and TNF- $\alpha$ production [Figure $6 \mathrm{~B}$ ].

\subsection{Inhibition of NET formation ameliorates DSS- induced colitis}

Next, we determined whether PAD4 expression was increased in an experimental mouse model of colitis, namely DSS-induced colitis. PAD4 RNA transcripts were significantly increased in inflamed colon of mice with DSS-colitis but not in control mice [Supplementary Figure 2A]

To better characterize the contribution of NET release in DSScolitis, we evaluated expression of PAD4 and citH3 during the course of colitis. Induction of such proteins was already evident by day 4, a time point at which no body weight loss was seen, suggesting that NETs can play a role in the initiation of colitis in this model [Supplementary Figure 2B, C]. To further address this issue, DSStreated mice were given streptonigrin, a selective PAD4 inhibitor, on day 4, and then followed until day 8. During the experimental procedures, there were neither visible toxic effects of the drug nor changes of animal behaviour. Streptonigrin alone did not affect mucosal architecture and epithelial integrity in normal animals [data not shown]. Because PAD4 promotes citrullination of histone $\mathrm{H} 3,{ }^{29}$ we verified the activity of streptonigrin by assessing citH3 expression by Western blotting and immunofluorescence. A marked reduction of citH3 was seen in the intestine of streptonigrin-treated mice as compared to DSS control animals [Figure 7A, B]. DSS-treated mice receiving intraperitoneal streptonigrin showed reduced colonic inflammation compared to DSS-treated mice, as indicated by the diminished weight loss, rectal bleeding and diarrhoea [Figure $7 \mathrm{C}$ ]. Moreover, histological examination of colonic samples as well as blinded histological scoring of colitis showed that streptonigrin was effective in attenuating the DSS-driven colonic inflammation [Figure $7 \mathrm{D}$ ] and reducing LCN-2, TNF- $\alpha$ and IL-1 $\beta$ RNA expression [Figure 7E].

\section{Discussion}

This study aimed to investigate the role of NETs in the control of mucosal inflammation in UC. Our data indicate that expression of both PAD4, a driver of NET release, and citH3 was increased in inflamed colon of UC patients as compared to NC. This confirms and expands on data from studies showing an increased abundance of NET-related proteins in $\mathrm{UC}^{21}$ and up-regulation of protein citrullination in human IBD colonic biopsies. ${ }^{33}$ Analysis of cell sources of PAD4 revealed that this protein was over-produced in both epithelial and lamina propria cells, some of which showed morphological features indicative of neutrophils. In contrast, no difference in PAD4 expression was seen between CD patients and NC, suggesting that induction of PAD4 in UC is not an epiphenomenon of the mucosal inflammation. Moreover, in UC, PAD4 was more expressed in inflamed mucosa than in uninvolved areas of the same patients, clearly indicating that induction of this protein is associated with the ongoing inflammation and does not rely on the current therapy. While this manuscript was in preparation, Angelidou et al. reported enhanced expression of NET components in UC but not CD mucosa. ${ }^{28}$

In line with data from previous studies, we also show that UC samples contain enhanced levels of MPO and NE, ${ }^{34,35}$ two additional components of NETs. Although these proteins can be secreted and act independently of NETs, our immunofluorescence analysis indicates that both MPO and NE co-localize with DNA and citH3,
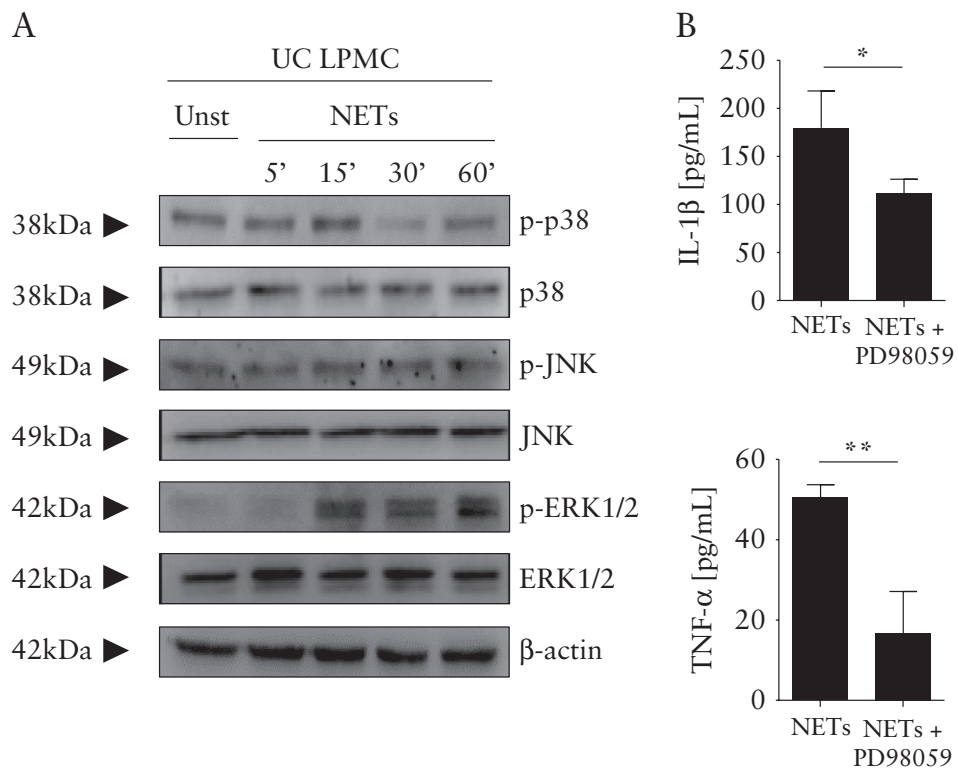

Figure 6. Neutrophil extracellular traps [NETs] enhance the production of IL-1 $\beta$ andTNF- $\alpha$ through an ERK-dependent mechanism in ulcerative colitis [UC] lamina propria mononuclear cells [LPMCs]. [A] UC LPMCs were either left untreated or treated with NETs for different time points [5, 10, 30 and 60 min]. Representative Western blot showing the expression of total and active [phosphorylated] forms of ERK1/2, p38 and JNK. $\beta$-Actin was used as a loading control. [B] PD98059, a specific inhibitor of ERK $1 / 2$ activation, reverts the stimulatory effect of NETs on TNF- $\alpha$ and IL-1 $\beta$ production. IL- $1 \beta$ and TNF- $\alpha$ protein expression was determined by ELISA. Data are mean \pm SEM of four experiments [ $\left.{ }^{*} p<0.05,{ }^{* *} p<0.01\right]$. 
A

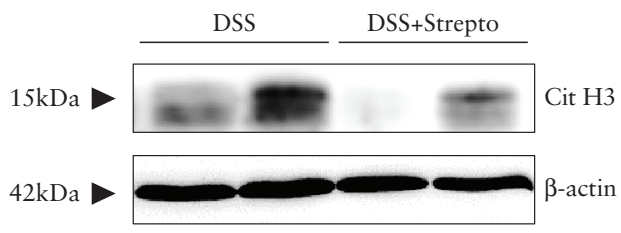

$\mathrm{B}$
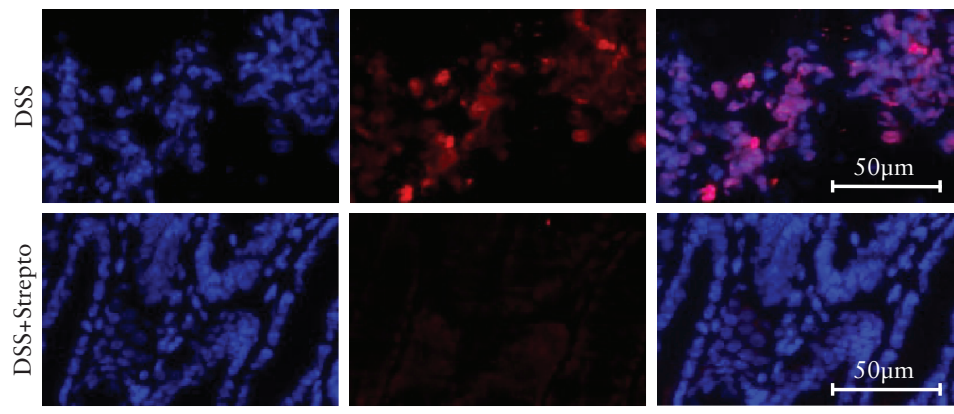

DNA; citH3
$\mathrm{C}$
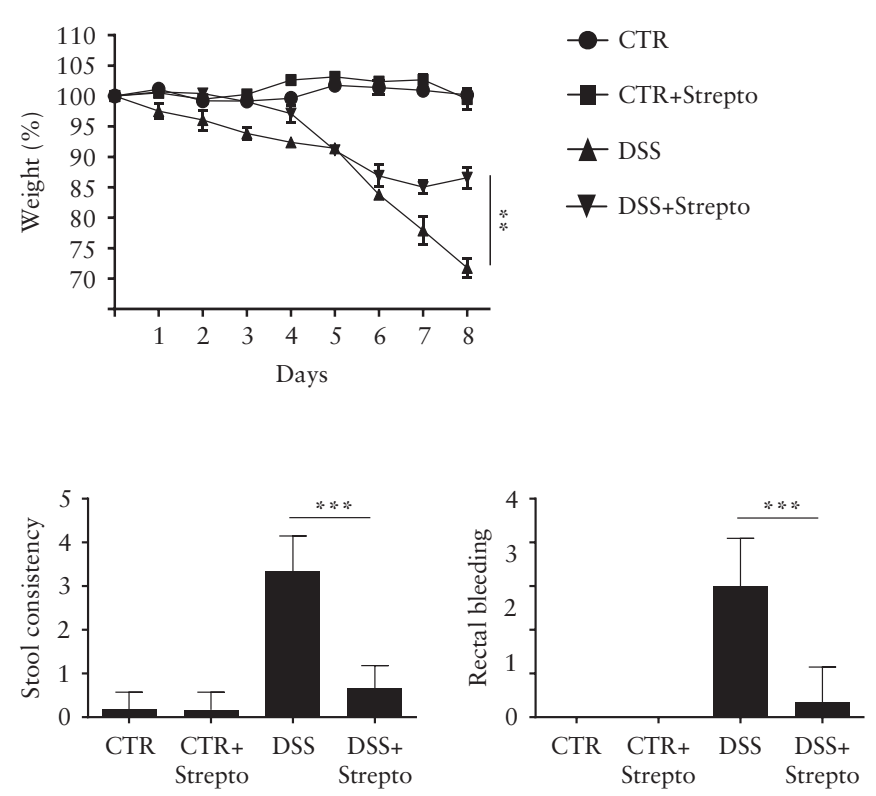

$\mathrm{D}$
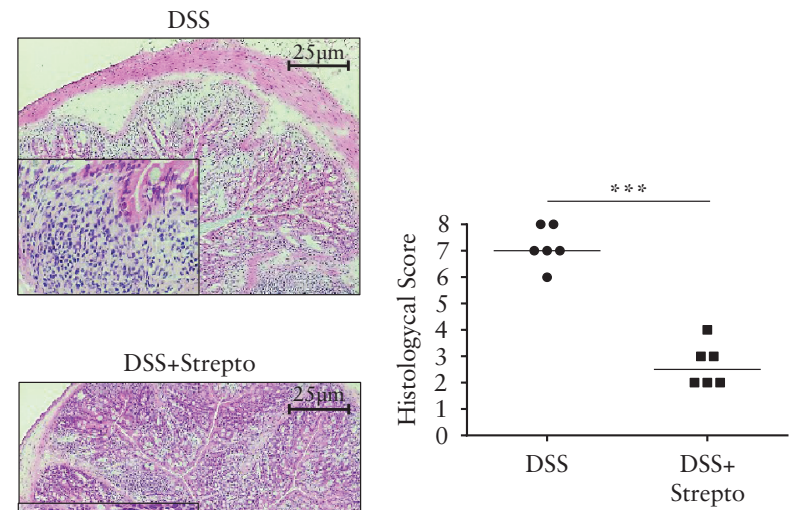

$\mathrm{E}$
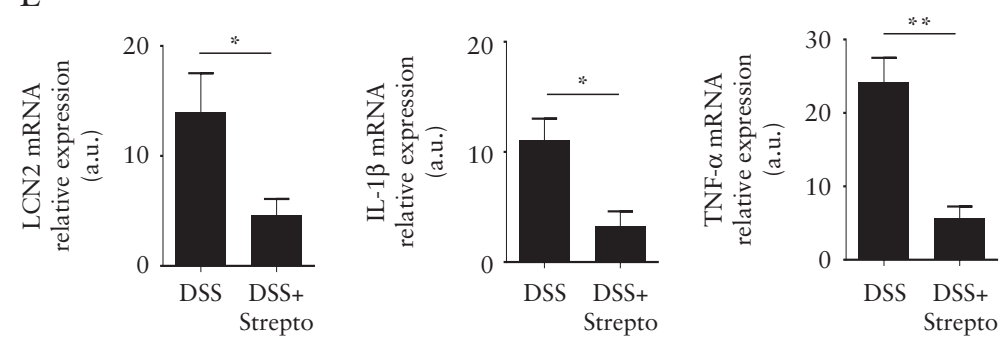

Figure 7. Inhibition of NET formation ameliorates dextran sulfate sodium [DSS]-induced colitis. [A] Representative Western blots showing citrullinated histone $\mathrm{H} 3$ [citH3] expression in mice receiving DSS either left untreated or treated with streptonigrin [DSS+Strepto]. $\beta$-Actin was used as a loading control. [B] Representative double-immunofluorescence staining of colonic mucosal sections of streptonigrin-treated mice and DSS control mice. citH3 [red], co-localizing with DNA, is reduced in streptonigrin-treated mice as compared to DSS control mice. [C] Mice received either regular drinking water [CTR] or DSS for 8 days. On day 4, mice were treated with PAD4 inhibitor, streptonigrin [DSS+Strepto], by intraperitoneal injection until the day on which they were killed. Control mice were either left untreated or treated with streptonigrin [CTR+Strepto] by intraperitoneal injection. Body weight was recorded daily and each point on the graph indicates cumulative mean \pm standard deviation [SD] of three separate experiments. Mice were also monitored daily for signs of rectal bleeding and stool consistency; each column in the graph represents cumulative mean \pm SD of all the experiments. In each experiment, at least six mice per group were included [** $p<0.01,{ }^{* *} p<0.005$ ]. [D] Representative H\&E-stained colonic sections of mice receiving DSS, left untreated [DSS] or treated with streptonigrin [DSS+Strepto]. Right inset shows the histological score of the colonic sections. Each point in the graph represents the score of a single mouse and horizontal bars indicate median values $[* * * p<0.005$ ]. [E] Streptonigrin reduces LCN2, TNF- $\alpha$ and IL-1 $\beta$ expression in the colon of DSStreated mice. RNA transcripts were analysed by real-time PCR and normalized to $\beta$-actin. Data are mean $\pm \mathrm{SEM}$ of three experiments [* $p<0.05, * * p<0.01]$. Values are expressed in arbitrary units [a.u.]. 
further supporting the hypothesis that NET release occurs in the active phases of UC.

Studies in other systems have shown that NETs can be formed not only in response to microbial peptides but also as a consequence of neutrophil stimulation with inflammatory cytokines, nitric oxide, monosodium urate crystals and various autoantibodies, and cell-cell interaction between neutrophils and platelets or activated endothelial cells. ${ }^{36-43}$ Our data support these findings, as we were able to show that neutrophils isolated from peripheral blood of UC patients responded to LPS and TNF- $\alpha$ with enhanced formation of NETs. Consistently, TNF- $\alpha$ blockade with IFX markedly reduced colonic expression of PAD4 and the presence of NETs in UC patients. These data may appear surprising, as PAD4 content did not differ between NC and CD, despite TNF- $\alpha$ being over-produced in $\mathrm{CD}$ mucosa. ${ }^{44}$ One possibility is that the prevalent induction of NET release in UC, but not in CD, is secondary to the preferential accumulation of neutrophils in the mucosa of UC patients. Accordingly, the reduced formation of NETs seen in infliximab-treated patients could be, at least in part, due to a decreased neutrophil infiltration of the mucosa. Further work is needed to better address this issue as well as to examine whether there is a cell-specific regulation of PAD4 in the gut and which function PAD4 exerts in additional cell types [e.g. epithelial cells] other than neutrophils. In this context, it is known that PAD4 deiminates histones $\mathrm{H} 2 \mathrm{~A}, \mathrm{H} 3$ and $\mathrm{H} 4$ and, hence, influences expression of several genes involved in cell growth and death..$^{45}$ Moreover, PAD4 regulates expression/activity of several proteins [e.g. inhibitor of growth 4, p300 and histone deacetylase 2], which are important in control of the DNA damage repair response, protein misfolding and protein inactivation. ${ }^{46-48}$

Because, in UC, NETs were predominant in mucosal areas with active inflammation, we next explored the possibility that such structures can contribute to amplify the local inflammation. Indeed, treatment of UC LMPCs with NETs increased the production of inflammatory cytokines, such as IL- $1 \beta$ and TNF- $\alpha$. In contrast, there was no significant change in the induction of TGF- $\beta 1$, thus excluding the possibility that the inducing effect of NETs on IL-1 $\beta$ and TNF$\alpha$ is secondary to suppression of counter-regulatory mechanisms. It is unlikely that induction of inflammatory cytokines in UC LPMC cultures following treatment with NETs is due to contaminants, as pre-treatment of NETs with DNase abolished the stimulatory effect of NETs on IL- $1 \beta$ and TNF- $\alpha$ synthesis. Our data indicate that UC NET-driven inducing effect on TNF- $\alpha$ secretion by UC LPMCs relies on NET-associated IL-1 $\beta$, as the addition of Anakinra to UC LPMC cultures abrogated such an effect. Surprisingly, Anakinra did not affect UC NET-stimulated IL-1 $\beta$ secretion, thus suggesting the existence of an alternative, IL-1 $\beta$-independent mechanism that controls the biological function of NETs in our cell system. This later finding appears to conflict with data published by Angelidou $e t$ al., who showed that UC NETs induce the production of pro-IL-1 $\beta$ in control peripheral blood mononuclear cells [PBMCs] through an IL-1 $\beta$-dependent mechanism. ${ }^{28}$ This discordance could rely on the fact that different cell sources of IL-1 $\beta$ were used in the two studies [i.e. PBMCs vs LPMCs]. It is also noteworthy that we measured the mature form of IL-1 $\beta$ while Angelidou et al. restricted their analysis to pro-IL-1 $\beta$, which is converted in mature IL- $1 \beta$ by caspase 1 , an enzyme largely activated in inflamed tissue of IBD patients. ${ }^{49}$

Identification of cell sources of IL- $1 \beta$ and TNF- $\alpha$ in our system is beyond the scope of this study. However, it is conceivable that antigen-presenting cells [APCs] can contribute to such synthesis, as these two cytokines are predominantly made by CD14-expressing APCs in $\mathrm{UC}^{50,51}$ and previous studies have shown that NETs stimulate macrophage lines to release inflammatory cytokines. ${ }^{52,53}$ Analysis of the basic mechanism underlying induction of inflammatory cytokines by NETs revealed that UC LPMCs treated with NETs exhibited enhanced phosphorylation of ERK1/2 and pharmacological inhibition of such a kinase with PD98059 significantly reduced NET-induced inflammatory cytokine production. In such experiments, PD98059 was used at a final concentration of $20 \mu \mathrm{M}$, a dose previously shown to selectively inhibit ERK1/2.54

To translate our data in vivo, we used an acute model of DSSinduced colitis, showing immune-morphological similarities with UC. Expression of PAD4 and citH3 protein was increased in the colon of mice receiving DSS and this induction occurred at early time points, suggesting a potential role of NETs in the pathogenesis of colitis. Therapeutic administration of streptonigrin, a highly potent PAD4 inhibitor, which blocks histone H3 citrullination, to colitic mice decreased expression of pro-inflammatory cytokines and neutrophil-related genes and attenuated colonic inflammation. These data are consistent with results of previous studies showing that $\mathrm{Cl}$-amidine, a pan-PAD inhibitor, inhibits DSS-colitis and colitis-associated tumorigenesis in mice. ${ }^{55,56}$ It is known that streptonigrin can exert PAD4-independent immunoregulatory and antimicrobial activity, and therefore we cannot exclude the possibility that the anti-inflammatory effect of the drug documented in this study may also rely on such activities. Moreover, the detrimental effect of abnormal NET release in the gut is supported by a recent paper showing that inhibition of PAD4 reduces tissue damage and mortality in a mouse model of necrotizing enterocolitis. ${ }^{57}$

In conclusion, this study shows excessive formation of NETs in UC and suggests a role for NETs in amplification of the inflammatory cascade in this disorder. Therefore, compounds interfering with NET release could be useful for dampening the detrimental immune response in UC.

\section{Funding}

No specific funding was received for this work.

\section{Conflict of Interest}

Giovanni Monteleone has served as an advisory board member for ABBVIE, while the remaining authors have no conflicts of interest to declare.

\section{Author Contributions}

VD and IMarafini performed experiments, analysed data and wrote the paper. DDF, FL, EF, ADG and MMF performed experiments and analysed data. FC provided human samples. CS and IMonteleone supervised parts of the project. GM designed the study, supervised the project and drafted the paper.

\section{Supplementary Data}

Supplementary data are available at ECCO-JCC online.

\section{References}

1. Ungaro R, Mehandru S, Allen PB, Peyrin-Biroulet L, Colombel JF. Ulcerative colitis. Lancet 2017;389:1756-70.

2. de Souza HS, Fiocchi C. Immunopathogenesis of IBD: current state of the art. Nat Rev Gastroenterol Hepatol 2016;13:13-27.

3. Kolaczkowska E, Kubes P. Neutrophil recruitment and function in health and inflammation. Nat Rev Immunol 2013;13:159-75. 
4. Brinkmann V, Reichard U, Goosmann C, et al. Neutrophil extracellular traps kill bacteria. Science 2004;303:1532-5.

5. Delgado-Rizo V, Martínez-Guzmán MA, Iñiguez-Gutierrez L, GarcíaOrozco A, Alvarado-Navarro A, Fafutis-Morris M. Neutrophil extracellular traps and its implications in inflammation: an overview. Front Immunol 2017;8:81.

6. Yang H, Biermann MH, Brauner JM, Liu Y, Zhao Y, Herrmann M. New insights into neutrophil extracellular traps: mechanisms of formation and role in inflammation. Front Immunol 2016;7:302.

7. Masuda S, Nakazawa D, Shida H, et al. NETosis markers: quest for specific, objective, and quantitative markers. Clin Chim Acta 2016;459:89-93.

8. Gupta S, Kaplan MJ. The role of neutrophils and NETosis in autoimmune and renal diseases. Nat Rev Nephrol 2016;12:402-13.

9. Qi H, Yang S, Zhang L. Neutrophil extracellular traps and endothelial dysfunction in atherosclerosis and thrombosis. Front Immunol 2017;8:928.

10. Cedervall J, Zhang Y, Olsson AK. Tumor-induced NETosis as a risk factor for metastasis and organ failure. Cancer Res 2016;76:4311-5.

11. Lood C, Blanco LP, Purmalek MM, et al. Neutrophil extracellular traps enriched in oxidized mitochondrial DNA are interferogenic and contribute to lupus-like disease. Nat Med 2016;22:146-53.

12. Pieterse E, Hofstra J, Berden J, Herrmann M, Dieker J, van der Vlag J. Acetylated histones contribute to the immunostimulatory potential of neutrophil extracellular traps in systemic lupus erythematosus. Clin Exp Immunol 2015;179:68-74.

13. Knight JS, Subramanian V, O'Dell AA, et al. Peptidylarginine deiminase inhibition disrupts NET formation and protects against kidney, skin and vascular disease in lupus-prone MRL/lpr mice. Ann Rheum Dis 2015;74:2199-206.

14. Yu Y, Koehn CD, Yue Y, et al. Celastrol inhibits inflammatory stimuli-induced neutrophil extracellular trap formation. Curr Mol Med 2015;15:401-10.

15. Khandpur R, Carmona-Rivera C, Vivekanandan-Giri A, et al. NETs are a source of citrullinated autoantigens and stimulate inflammatory responses in rheumatoid arthritis. Sci Transl Med 2013;5:178ra40.

16. Yalavarthi S, Gould TJ, Rao AN, et al. Release of neutrophil extracellular traps by neutrophils stimulated with antiphospholipid antibodies: a newly identified mechanism of thrombosis in the antiphospholipid syndrome. Arthritis Rheumatol 2015;67:2990-3003.

17. Martínez-Alemán SR, Campos-García L, Palma-Nicolas JP, HernándezBello R, González GM, Sánchez-González A. Understanding the entanglement: neutrophil extracellular traps (NETs) in cystic fibrosis. Front Cell Infect Microbiol 2017;7:104.

18. Gray RD, Hardisty G, Regan KH, et al. Delayed neutrophil apoptosis enhances NET formation in cystic fibrosis. Thorax 2018;73:134-44.

19. Wong SL, Demers M, Martinod K, et al. Diabetes primes neutrophils to undergo NETosis, which impairs wound healing. Nat Med 2015;21:815-9.

20. Hu SC, Yu HS, Yen FL, Lin CL, Chen GS, Lan CC. Neutrophil extracellular trap formation is increased in psoriasis and induces human $\beta$-defensin-2 production in epidermal keratinocytes. Sci Rep 2016;6:31119.

21. Bennike TB, Carlsen TG, Ellingsen T, et al. Neutrophil extracellular traps in ulcerative colitis: a proteome analysis of intestinal biopsies. Inflamm Bowel Dis 2015;21:2052-67.

22. Dreyton CJ, Anderson ED, Subramanian V, Boger DL, Thompson PR. Insights into the mechanism of streptonigrin-induced protein arginine deiminase inactivation. Bioorgan Med Chem 2014;22:1362-9.

23. Ham A, Rabadi M, Kim M, et al. Peptidyl arginine deiminase-4 activation exacerbates kidney ischemia-reperfusion injury. Am J physiol Renal physiol 2014;307:F1052-62.

24. Li L, Wang L, Wu Z, et al. Anthocyanin-rich fractions from red raspberries attenuate inflammation in both RAW264.7 macrophages and a mouse model of colitis. Sci Rep 2014;4:6234.

25. Monteleone I, Rizzo A, Sarra M, et al. Aryl hydrocarbon receptor-induced signals up-regulate IL-22 production and inhibit inflammation in the gastrointestinal tract. Gastroenterology 2011;141:237-48, 248.e1.

26. Monteleone I, Marafini I, Dinallo V, et al. Sodium chloride-enriched diet enhanced inflammatory cytokine production and exacerbated experimental colitis in mice. J Crohns Colitis 2017;11:237-45.
27. von Köckritz-Blickwede M, Chow OA, Nizet V. Fetal calf serum contains heat-stable nucleases that degrade neutrophil extracellular traps. Blood 2009;114:5245-6.

28. Angelidou I, Chrysanthopoulou A, Mitsios A, et al. REDD1/autophagy pathway is associated with neutrophil-driven IL-1 $\beta$ inflammatory response in active ulcerative colitis. J Immunol 2018;200:3950-61.

29. Li P, Li M, Lindberg MR, Kennett MJ, Xiong N, Wang Y. PAD4 is essential for antibacterial innate immunity mediated by neutrophil extracellular traps. J Exp Med 2010;207:1853-62.

30. Jones JE, Causey CP, Knuckley B, Slack-Noyes JL, Thompson PR. Protein arginine deiminase 4 (PAD4): current understanding and future therapeutic potential. Curr Opin Drug Discov Devel 2009;12:616-27.

31. Kuno Y, Ina K, Nishiwaki T, et al. Possible involvement of neutrophil elastase in impaired mucosal repair in patients with ulcerative colitis. $J$ Gastroenterol 2002;37[Suppl 14]:22-32.

32. Chami B, Martin NJJ, Dennis JM, Witting PK. Myeloperoxidase in the inflamed colon: a novel target for treating inflammatory bowel disease. Arch Biochem Biophys 2018;645:61-71.

33. Makrygiannakis D, af Klint E, Lundberg IE, et al. Citrullination is an inflammation-dependent process. Ann Rheum Dis 2006;65:1219-22.

34. Gouni-Berthold I, Baumeister B, Wegel E, Berthold HK, Vetter H, Schmidt C. Neutrophil-elastase in chronic inflammatory bowel disease: a marker of disease activity? Hepatogastroenterology 1999;46:2315-20.

35. Kristjánsson G, Venge P, Wanders A, Lööf L, Hällgren R. Clinical and subclinical intestinal inflammation assessed by the mucosal patch technique: studies of mucosal neutrophil and eosinophil activation in inflammatory bowel diseases and irritable bowel syndrome. Gut 2004;53:1806-12.

36. Keshari RS, Jyoti A, Dubey M, et al. Cytokines induced neutrophil extracellular traps formation: implication for the inflammatory disease condition. pLoS One 2012;7:e48111.

37. Neeli I, Khan SN, Radic M. Histone deimination as a response to inflammatory stimuli in neutrophils. J Immunol 2008;180:1895-902.

38. Patel S, Kumar S, Jyoti A, et al. Nitric oxide donors release extracellular traps from human neutrophils by augmenting free radical generation. Nitric Oxide 2010;22:226-34.

39. Gupta AK, Joshi MB, Philippova M, et al. Activated endothelial cells induce neutrophil extracellular traps and are susceptible to NETosismediated cell death. FEBS Lett 2010;584:3193-7.

40. Clark SR, Ma AC, Tavener SA, et al. Platelet TLR4 activates neutrophil extracellular traps to ensnare bacteria in septic blood. Nat Med 2007;13:463-9.

41. Kaplan MJ, Radic M. Neutrophil extracellular traps: double-edged swords of innate immunity. J Immunol 2012;189:2689-95.

42. Mitroulis I, Kambas K, Chrysanthopoulou A, et al. Neutrophil extracellular trap formation is associated with IL- $1 \beta$ and autophagy-related signaling in gout. pLoS One 2011;6:e29318.

43. Lande R, Ganguly D, Facchinetti V, et al. Neutrophils activate plasmacytoid dendritic cells by releasing self-DNA-peptide complexes in systemic lupus erythematosus. Sci Transl Med 2011;3:73ra19.

44. Torres J, Mehandru S, Colombel JF, Peyrin-Biroulet L. Crohn's disease. Lancet 2017;389:1741-55.

45. Nakashima K, Hagiwara T, Ishigami A, et al. Molecular characterization of peptidylarginine deiminase in HL-60 cells induced by retinoic acid and 1 $\alpha, 25$-dihydroxyvitamin $\mathrm{D}_{3}$.J Biol Chem 1999;274:27786-92.

46. Lee YH, Coonrod SA, Kraus WL, Jelinek MA, Stallcup MR. Regulation of coactivator complex assembly and function by protein arginine methylation and demethylimination. proc Natl Acad Sci U S A 2005;102:3611-6.

47. Guo Q, Fast W. Citrullination of inhibitor of growth 4 (ING4) by peptidylarginine deminase 4 (PAD4) disrupts the interaction between ING4 and p53. J Biol Chem 2011;286:17069-78.

48. Li P, Wang D, Yao H, et al. Coordination of PAD4 and HDAC2 in the regulation of p53-target gene expression. Oncogene 2010;29:3153-62.

49. Monteleone G, Trapasso F, Parrello T, et al. Bioactive IL-18 expression is up-regulated in Crohn's disease. J Immunol 1999;163:143-7.

50. Rugtveit J, Haraldsen G, Høgåsen AK, Bakka A, Brandtzaeg P, Scott H. Respiratory burst of intestinal macrophages in inflammatory bowel 
disease is mainly caused by $\mathrm{CD} 14+\mathrm{L} 1+$ monocyte derived cells. Gut 1995;37:367-73.

51. Rugtveit J, Nilsen EM, Bakka A, Carlsen H, Brandtzaeg P, Scott H. Cytokine profiles differ in newly recruited and resident subsets of mucosal macrophages from inflammatory bowel disease. Gastroenterology 1997;112:1493-505.

52. Hu Z, Murakami T, Tamura H, et al. Neutrophil extracellular traps induce IL-1 $\beta$ production by macrophages in combination with lipopolysaccharide. Int J Mol Med 2017;39:549-58.

53. Nakazawa D, Shida H, Kusunoki Y, et al. The responses of macrophages in interaction with neutrophils that undergo NETosis. J Autoimmun 2016;67:19-28.
54. Franzè E, Dinallo V, Rizzo A, et al. Interleukin-34 sustains pro-tumorigenic signals in colon cancer tissue. Oncotarget 2018;9:3432-45.

55. Chumanevich AA, Causey CP, Knuckley BA, et al. Suppression of colitis in mice by $\mathrm{Cl}$-amidine: a novel peptidylarginine deiminase inhibitor. $\mathrm{Am} \mathrm{J}$ physiol Gastrointest Liver physiol 2011;300:G929-38.

56. Witalison EE, Cui X, Causey CP, Thompson PR, Hofseth LJ. Molecular targeting of protein arginine deiminases to suppress colitis and prevent colon cancer. Oncotarget 2015;6:36053-62.

57. Vincent D, Klinke M, Eschenburg G, et al. NEC is likely a NETs dependent process and markers of NETosis are predictive of NEC in mice and humans. Sci Rep 2018;8:12612. 